
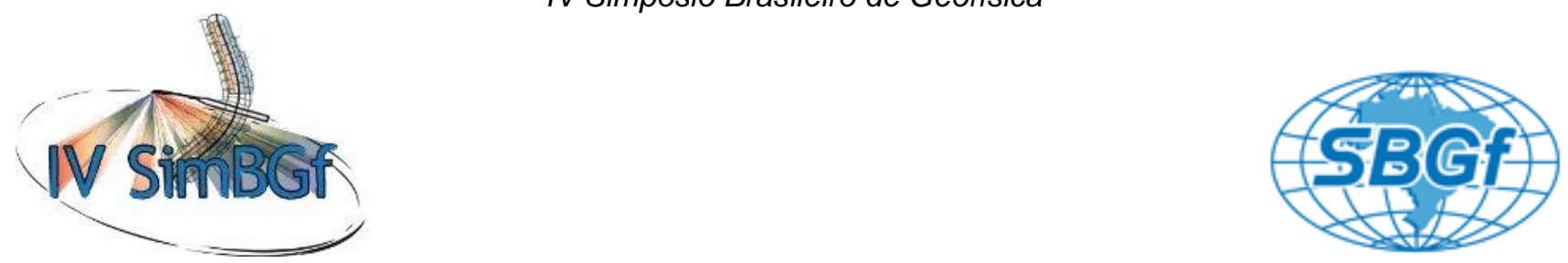

\title{
Descoberta geofísica com o uso de GPR em antiga base militar da época da Guerrilha do Araguaia - PA - Brasil
}

PEDROSA JÚNIOR, Nilo Costa (1); RUSSO, Daniel (2); BLUM, Marcelo de Lawrence Bassay (2); BORGES, Welitom Rodrigues (3); CASTELO BRANCO, Raimundo Mariano Gomes (1).

(1) Laboratório de Geofísica-Universidade Federal do Ceará. (2) Departamento de Polícia Federal. (3) Universidade de Brasília.

Copyright 2010, SBGf - Sociedade Brasileira de Geofísica

Este texto foi preparado para a apresentação no IV Simpósio Brasileiro de Geofísica, Belém, 14 a 17 de novembro de 2010. Seu conteúdo foi revisado pelo Comitê Técnico do IV SimBGf, mas não necessariamente representa a opinião da SBGf ou de seus associados. É proibida a reprodução total ou parcial deste material para propósitos comerciais sem prévia autorização da SBGf.

\begin{abstract}
During Ground Penetrating Radar (GPR) field works, processing and interpretations to find human remains from Araguaia Guerrilla in an old army base, Para State (Brazil), several large metallic objects were found employing an antenna with center frequency of $400 \mathrm{MHz}$. These objects were found at depths between 0,2 and 1,42 meters. After analysis of the pieces revealed inside the geophysical anomalies, it was determined that all of them were part of an old SUV.
\end{abstract}

\section{Introdução}

Com o objetivo de verificar a existência de um poço com possíveis ossos de guerrilheiros que participaram do evento histórico conhecido como Guerrilha do Araguaia (1972-1974), uma equipe de geofísicos se deslocou para a Fazenda Bacaba, antiga base do Exército Brasileiro nos anos 70, localizada a 13 quilômetros a leste da cidade de São Domingos do Araguaia (Figura 1).

Neste trabalho, os autores descrevem a metodologia empregada, o processamento e interpretações, bem como tecem considerações sobre os objetos encontrados a partir da interpretação dos dados geofísicos coletados.

\section{Metodologia/ Problema Investigado}

Os exames foram realizados pela observação direta dos vestígios no local, pelo registro fotográfico e pela aquisição de dados de GPR em polígono que envolvia a área indicada pelos observadores do Grupo de Trabalho Tocantins - GTT dentro da área da fazenda Bacaba. Nas aquisições de dados foi utilizado o equipamento GPR da GSSI acoplado a antena blindada com freqüência centrada de $400 \mathrm{MHz}$ do mesmo fabricante (Figura 2). O registro fotográfico foi realizado com câmeras fotográficas digitais, a localização geodésica e mapeamento topográfico foram obtidos com o auxílio da equipe de cartografia do Centro de Imagens e Informações Geográficas do Exército - CIGEx que utilizou os receptores GPS (Global Positioning System) da marca
Trimble 5700 L1/L2 e estação Topcom GTS 239, com sessão controle de qualidade do projeto radiografia da Amazônia, utilizando o datum horizontal SIRGAS 2000.

Dentre os parâmetros de campo utilizados para a coleta de dados GPR, incluem-se: espaçamento entre os traços de 0,02 metros, 1024 amostras por traço, janelas temporais de até 90 ns (nanossegundos) e a freqüência de amostragem de $2400 \mathrm{MHz}$. Os traços foram registrados continuamente com 0 auxílio de um odômetro acoplado à roda. As seções de GPR foram coletadas a cada 0,50 metros no interior do polígono na direção N15E.

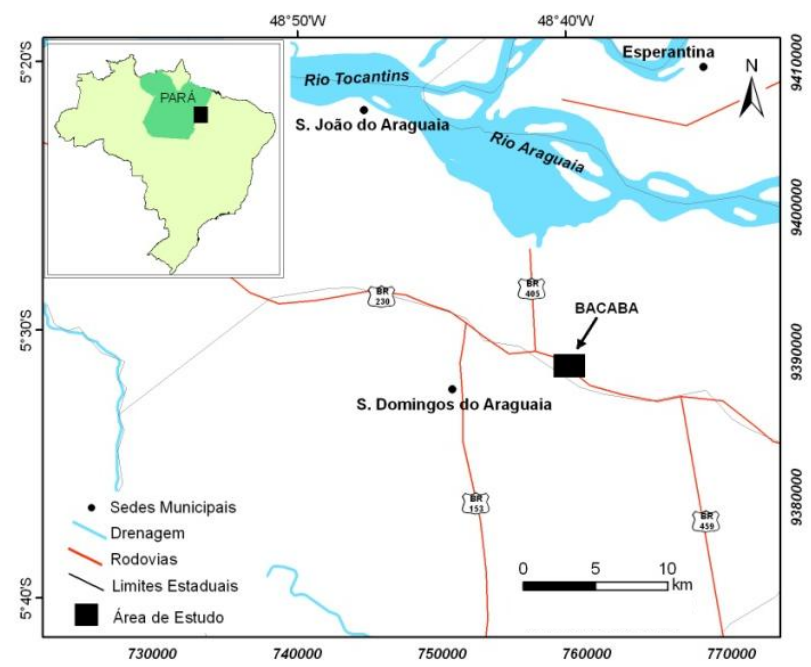

Figura 1 - Localização da área examinada.

Os dados foram processados no software ReflexW, versão 5.0 (Sandmeier, 2009). A rotina de processamento consistiu em conversão de formato do arquivo, ajuste do tempo zero, filtros temporal (dewow e passa-banda), ganho (decaimento de energia), migração no domínio do tempo (fk migration - Stolt) e conversão de tempo de propagação em profundidade utilizando velocidade eletromagnética constante calculada por ajuste hiperbólico. Este ajuste foi efetuado utilizando uma cabeça de picareta metálica como alvo a 0,50 metros de profundidade. A velocidade média obtida foi de 0,135 $\mathrm{m} / \mathrm{ns}$ (metros por nanossegundo), utilizada na inversão dos dados (Figura 3). 


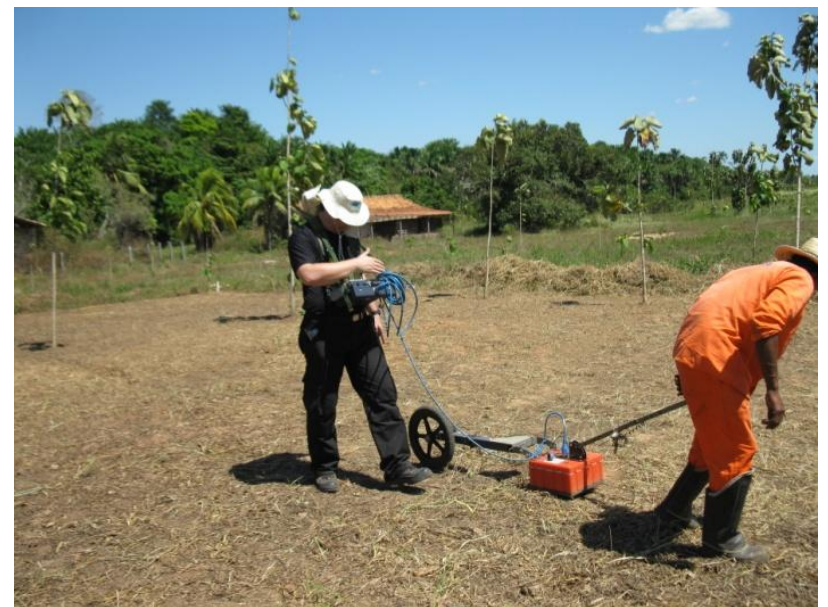

Figura 2 - Fotografia da aquisição utilizando o GPR com antena blindada de $400 \mathrm{MHz}$.

As etapas de processamento foram aplicadas de acordo com as características dos dados e dependerão, fundamentalmente, dos intérpretes. Uma vez escolhido o fluxo de processamento para uma seção GPR, o mesmo foi aplicado às outras seções.

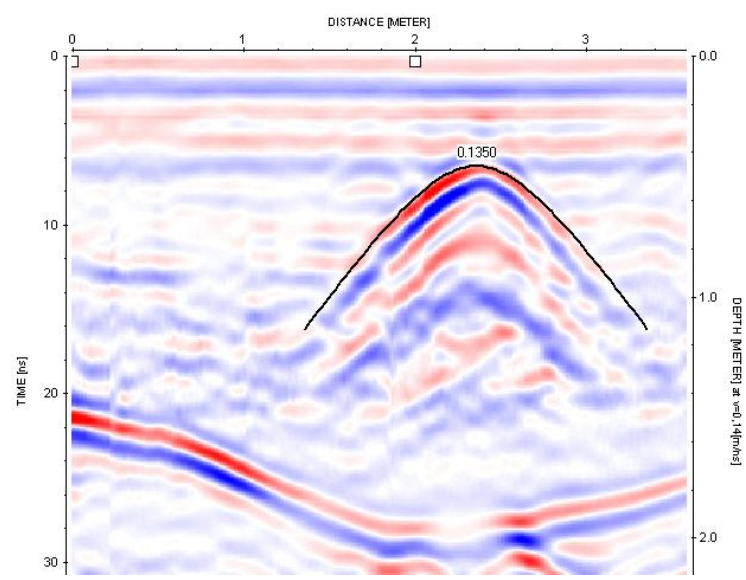

Figura 3 - Velocidade calculada por ajuste hiperbólico.

\section{Resultados}

Foi obtido um total de 30 seções GPR de aproximadamente 25 metros de comprimento em uma área de $350 \mathrm{~m}^{2}$. Durante o processo de limpeza da área foram observadas marcas típicas de implementos agrícolas no solo e foram achados alguns fragmentos de antigas construções, como tijolos e cimento, além de peças de metais enferrujadas.

Os resultados do levantamento GPR foram analisados através de seções 2D, individualmente (Figura 4).

$\mathrm{Na}$ análise das seções 2D, foram observadas presença de diversas anomalias que, somadas, indicavam um conjunto de objetos ou um grande e complexo objeto.

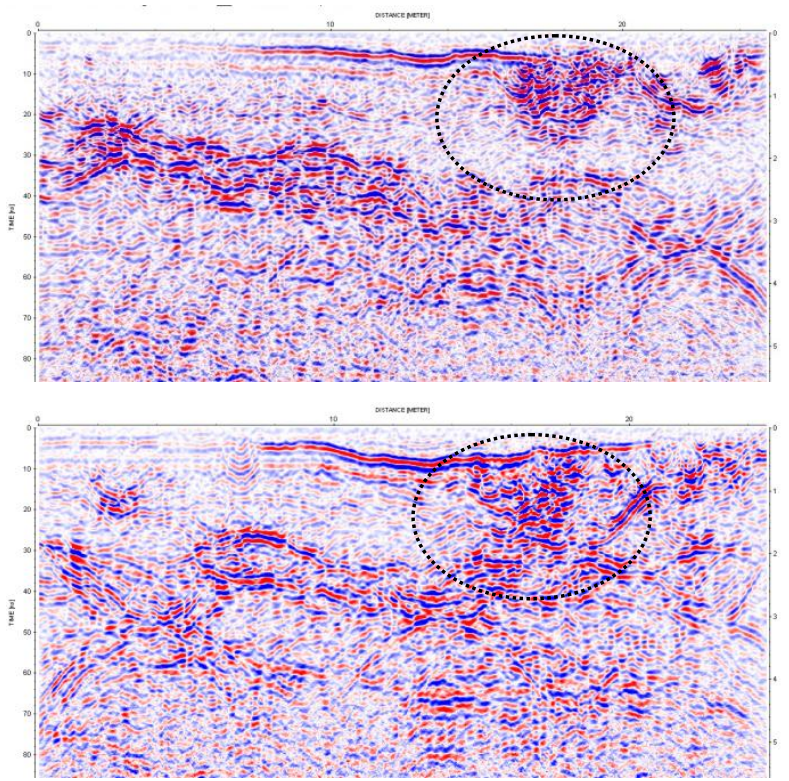

Figura 4 - Seções 2D com o alvo indicado.

$\mathrm{Na}$ análise do bloco 3D gerado, foi observado a possibilidade de um objeto com dimensões aproximadas de 1,5 metros de raio por 2,0 metros de profundidade (Figuras 5 e 8 ).

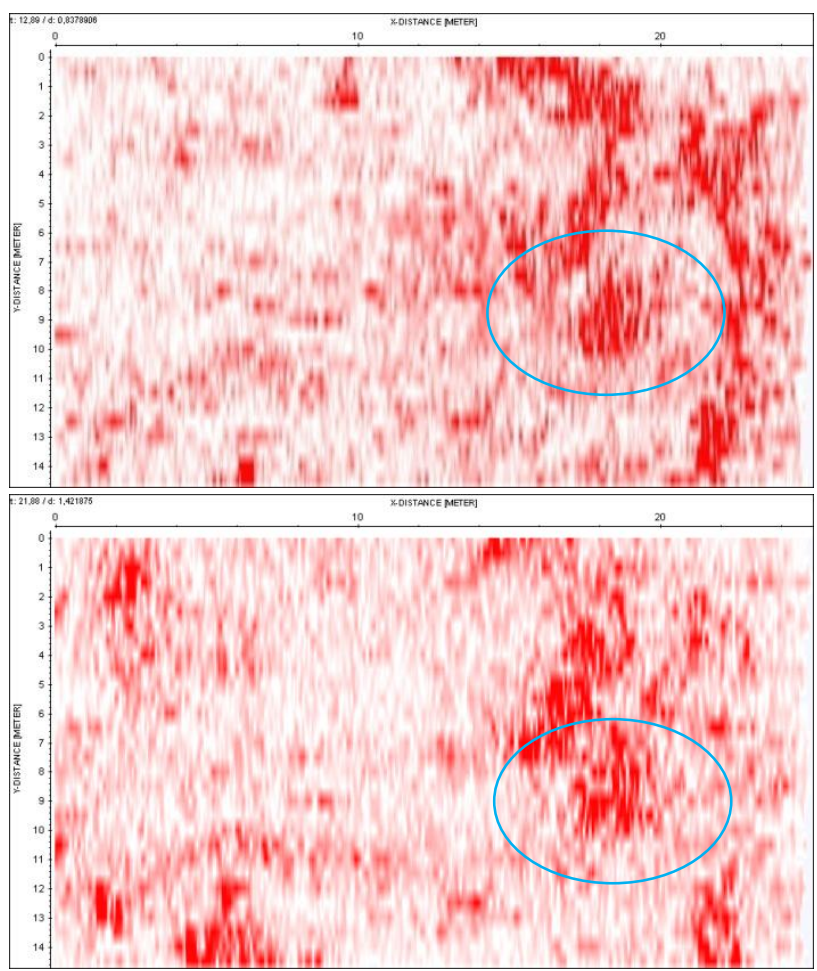

Figura 5 - Fatias de duas profundidades distintas acima 0,83 metros e abaixo 1,42 metros.

Após os procedimentos e dados apresentados anteriormente procedeu-se a perfuração-escavação do 
terreno investigado seguindo os alvos indicados pela geofísica.

Na profundidade de 0,20 metros encontrou-se um objeto metálico que se estendeu até a profundidade 1,45 metros (Figura 6). Além desse grande objeto, foram encontrados outros artefatos, tais como latas, tampas metálicas de recipientes, um talher, garrafas e entulhos diversos.

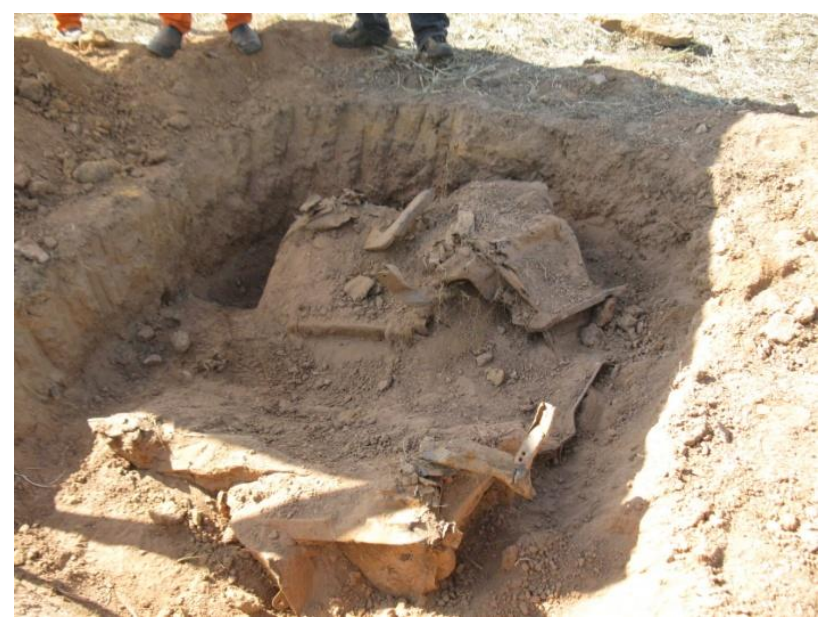

Figura 6 - Objeto escavado no local do alvo identificado.

Foram observados três horizontes no solo escavado. $\mathrm{O}$ primeiro com 0,20 metros de espessura um solo arenoso com material orgânico e coloração cinza. Entre a profundidade de 0,20 e 1,40 metros foi encontrado grande quantidade de restos de materiais de construção (entulho) e lixo em meio ao solo arenoso cinza/avermelhado. A partir de 1,45 foi encontrado solo homogêneo sem detritos, com coloração avermelhada e sem a presença de outros objetos.

\section{Discussão e Conclusões}

O objetivo do GTT é o de encontrar ossadas de seres humanos que combateram no episódio histórico conhecido como Guerrilha do Araguaia (1972-1974).

As características observadas nos fragmentos metálicos, encontrados com o auxílio do GPR, indicam que estes objetos são de uma carcaça de veículo automotor, possivelmente do tipo camionete (Figura 7). Em nenhum dos objetos encontrados, salvo melhor juízo, havia indícios de que pertenceram à época do evento histórico estudado.

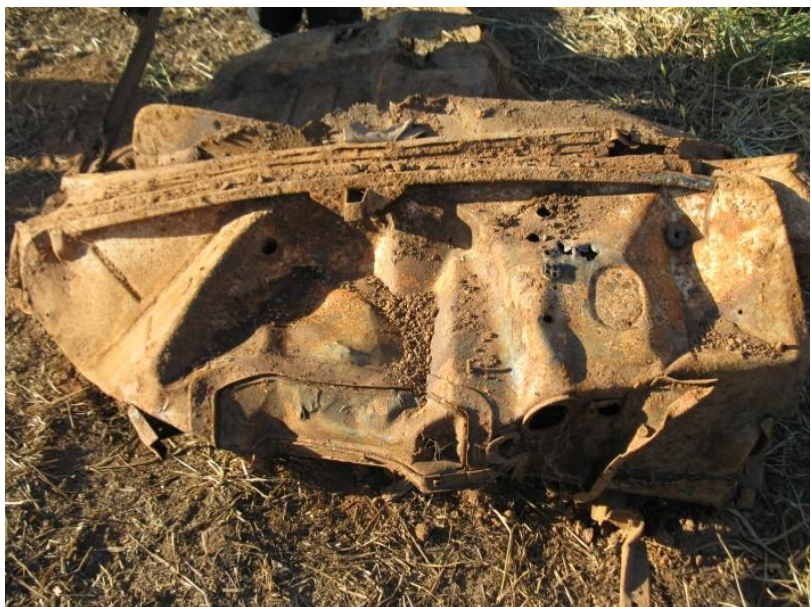

Figura 7 - Carcaça de veículo.

\section{Agradecimentos}

Ao Exército Brasileiro, pela logística e levantamentos geodésico e topográfico.

Ao Grupo Trabalho Tocantins - GTT pelo gigantesco apoio e ao.

Instituto Médico Legal IML - DF, em especial ao Dr. Ricardo (Monstro) Frade Nogueira, pela ajuda nos levantamentos com GPR e pelo bom humor ao sol do Araguaia.

\section{Referências}

Sandmeier, K.J., 2009. Sandmeier Software, Alemanha. 


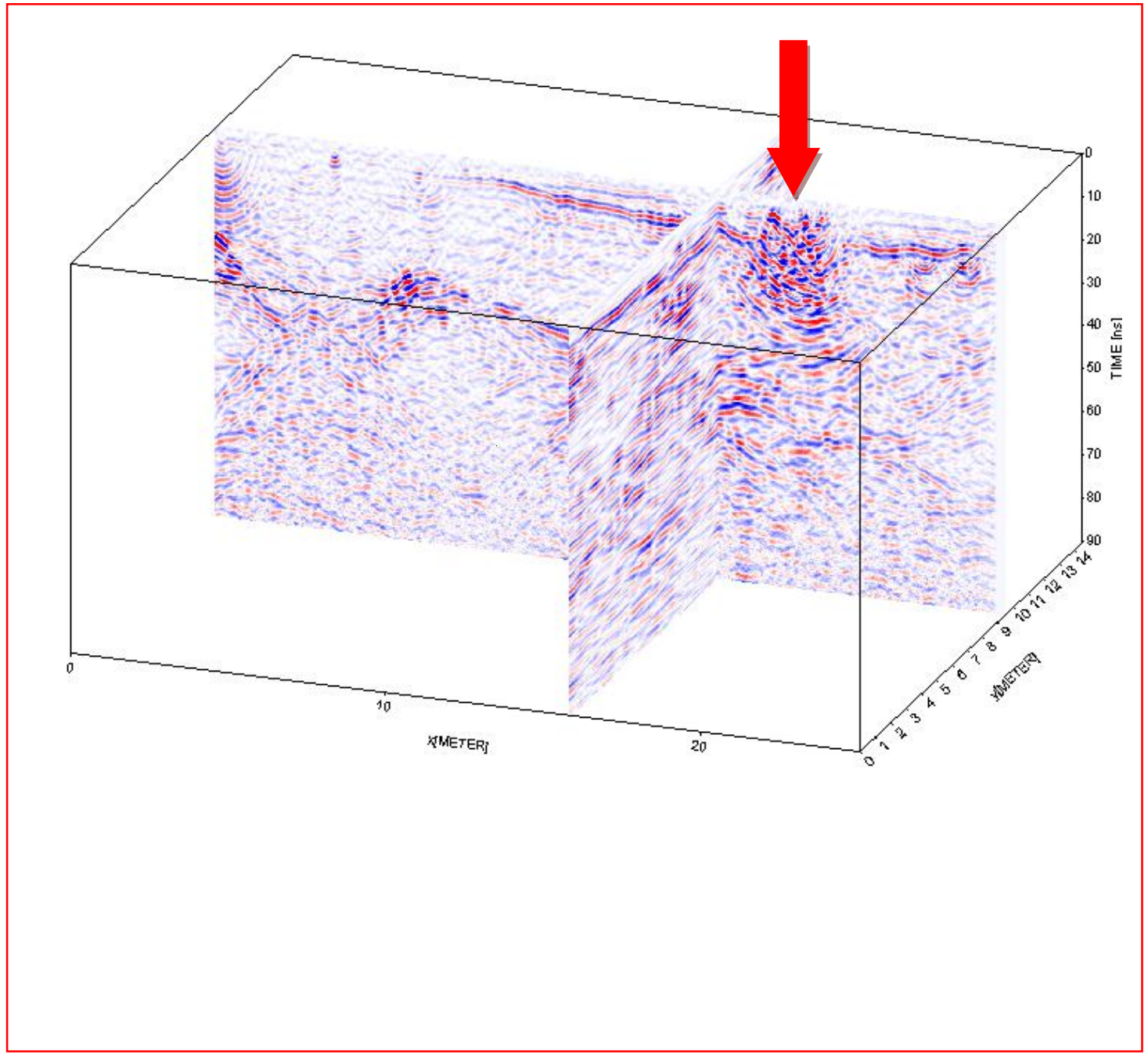

Figura 8 - Bloco 3D com indicação do alvo a ser escavado. 